position of the lesion on the cervix, ${ }^{27}$ and the presence of possible cofactors such as herpes viruses in carcinogenesis.

1 Richart RM. Cervical intraepithelial neoplasia: a review. In: Sommers SC, ed. Pathology annual, 1973. New York: Appleton-Century-Crofts, 1973:301-28. De Villiers EM. Heterogeneity of the human papillomavirus group. $f$ Virol 1989;63:4898-903.

3 Ikenberg $\mathrm{H}$. Human papillomavirus DNA in invasive genital carcinomas. In: Gross G, Jablonska S, Pfister H, Stegner HE, eds. Genital papillomavinu infections. Berlin: Springer Verlag, 1990:87-112.

4 Van den Brule AJC, Snijders PJF, Gordijn RLJ, Bleker OP, Meijer CJLM, Walboomers JMM. General primer-mediated polymerase chain reaction permits the detection of sequenced and still unsequenced human papillomapermits the detection of sequenced and still unsequenced human papilloma-
virus genotypes in cervical scrapes and carcinomas. Int 7 Cancer 1990;45 virus

5 Bennett Jenson A, Lancaster WD. Association of human papillomavirus with benign, premalignant, and malignant anogenital lesions. In: Pfister $\mathrm{H}$, ed. Papillomaviruses and human cancer. Boca Raton, Florida: CRC Press, 1990:12-43.

6 Winkelstein W Jr. Smoking and cervical cancer--current status: a review. Am f Epidemiol 1990;131:945-57.

7 Rohan T, Mann V, McLaughlin J, Hamish DG, Yu H, Smith D, et al. PCR detected genital papillomavirus infection: prevalence and association with risk factors for cervical cancer. Int 9 Cancer 1991;49:856-60.

8 Rotkin ID. A comparison review of key epidemiologic studies in cervica cancer related to current searches for transmissible agents. Cancer Res 1973;33:1353-67.

9 Clarke EA, Morgan RW, Newman AC. Smoking as a risk factor in cancer of the cervix: additional evidence from a case-control study. $A m \mathcal{F}$ Epidemiol 1982;115:59-66.

10 Lyon JL, Gardner JW, West DW, Stanish WM, Hebertson RM. Smoking and carcinoma in situ of the uterine cervix. Am $\mathcal{F}$ Public Health 1983;73:558-62

11 Trevathan E, Layde P, Webster LA, Adams JB, Benigno BB, Ory H Cigarette smoking and dysplasia and carcinoma in situ of the uterine cervix IAMA 1983;250:499-502.

12 Brinton LA, Schairer C, Haenszel W, Stolley P, Lehman HF, Levine R, et al. Cigarette smoking and invasive cervical cancer. $f A M A$ 1986;255:3265-9.

13 Melchers W, Van den Brule A, Walboomers J, De Bruin M, Burger M, Herbrink $P$, et al. Increased detection rate of human papilomavirus in cervical scrapes by the polymerase chain reaction as compared to modified FISH and Southern-blot analysis. $\mathcal{F}$ Med Virol 1989;27:329-35.

14 Claas E, Melchers W, van den Linden J, Lindeman J, Quint W. Human papillomavirus detection in paraffin embedded cervical carcinomas and their metastases by the polymerase chain reaction. Am f Pathol 1989;135:703-9.

15 Breslow NE, Day NE. Statistical methods in cancer research. Vol 1. The analyis f case-coln of case-control studies. Lyons: International Agency to

16 Comelissen MTE, Van den Tweel JG, Struyk APHB, Jebbink MF, Briët M Van der Noordaa J, et al. Localization of human papillomavirus type 16 Van der Noordaa J, et al. Localization of human papillomavirus type 16
DNA using the polymerase chain reaction in the cervix uteri of women with DNA using the polymerase chain reaction in the cervix uteri of
cervical intraepithelial neoplasia. $f$ Gen Virol 1989;70:2555-62.

17 Syrjänen K, Syriänen S. Concept of the existence of human papillomavirus (HPV) DNA in histologically normal squamous epithelium of the genital tract should be re-evaluated. Acta Obstet Gynecol Scand 1989;68:613-7.

18 Zur Hausen H. Papillomavirus in anogenital cancer: the dilemma of epidemiologic approaches. I Natl Cancer Inst 1989;81:1680-2.

19 Campion MJ, McCance DJ, Cuzick J, Singer A. Progressive potential of mild cervical atypia: prospective cytological and virological study. Lancet 1986;ii 237-40.

20 Barrasso R, Coupez F, Ionesco M, De Brux J. Human papilloma viruses and cervical intraepithelial neoplasia: the role of colposcopy. Gynecol Oncol 1987;27:197-207.

21 Dutch Foundation of Public Health and Smoking. Annual Repon 1990. The Hague: DFPHS, 1991

22 Holly EA, Perrakis NL, Friend NF, Sarles DL, Lee R, Flander LB. Mutagenic mucus in the cervix of smokers. $\mathcal{F}$ Natl Cancer Inst 1986;76: $983-6$

23 Sasson IM, Haley NJ, Hoffmann D, Wynder EL, Hellberg D, Nilsson S Cigarette smoking and neoplasia of the uterine cervix: smoke constituents in cervical mucus. N Engl f Med 1985;312:315-6.

24 Barton SE, Maddox PH, Jenkins D, Edwards R, Cuzick J, Singer A. Effect of cigarette smoking on cervical epithelial immunity: a mechanism for neoplastic change? Lancet 1988;ii:652-4.

25 Kramer MS. Clinical epidemiology and biostatistics. Berlin: Springer Verlag, 1988:60

26 Richart RM. A modified terminology for cervical intraepithelial neoplasia. Obstet Gynecol 1990;75:131-3.

27 Saito K, Saito A, Fu YS, Smotkin D, Gupta J, Shah K. Topographic study of cervical condyloma and intraepithelial neoplasia. Cancer 1987;59:2064-70.

(Accepted 31 December 1992)

\title{
Randomised comparison of combination chemotherapy plus supportive care with supportive care alone in patients with metastatic colorectal cancer
}

\author{
Werner Scheithauer, Harald Rosen, Gabriela-Verena Kornek, Christian Sebesta, Dieter Depisch
}

Division of Oncology, Department of Internal Medicine I, Vienna University Medical School, A-1090 Vienna, Austria Werner Scheithauer, senior lecturer

Gabriela-Verena Kornek, medical assistant

\section{Department of}

Gastroenterology,

Hanusch Hospital, A-1140

Vienna, Austria

Harald Rosen, senior

physician

Christian Sebesta, senior

plivsician

Department of Surgery,

Weiner Neustadt General

Hospital, A-2700 Weiner

Neustadt, Austria

Dieter Depisch, professor

Correspondence to:

Dr Scheithauer.

BMF 1993;306:752-5
Abstract

Objectives-To compare the length of survival and quality of life in patients given combination chemotherapy in addition to supportive care and in patients given only supportive care.

Design-Randomised study.

Setting-Gastrointestinal oncology departments.

Patients-40 previously untreated patients with histologically confirmed, measurable colorectal cancer that was locally recurrent or metastatic.

Interventions-Patients were allocated randomly to receive chemotherapy or only supportive care in a ratio of 2:1 according to performance status, metastatic disease of the liver, and weight loss in the six months before entering the study. Chemotherapy consisted of four week cycles of intravenous leucovorin $\left(200 \mathrm{mg} / \mathrm{m}^{2} /\right.$ day $)$ followed by 5 -fluorouracil $\left(550 \mathrm{mg} / \mathrm{m}^{2} /\right.$ day) and cisplatin $\left(20 \mathrm{mg} / \mathrm{m}^{2} /\right.$ day $)$, each drug being given on the first four days of the cycle.

Main outcome measures-Length of survival and quality of life score with an optimised functional living index-cancer scale.

Results-Overall survival was significantly longer for patients given chemotherapy ( 11.0 months) than for those receiving supportive care alone $\mathbf{5 . 0}$ months; $p=0 \cdot 006$ ). Despite common association of chemotherapy with mild to moderate gastrointestinal symptoms, there was no significant difference between the two groups in global or subgroup quality of life scores. In patients with abnormal scores before treatment, quality of life seemed better in the chemotherapy arm.

Conclusions-In this sample of patients with dis- seminated colorectal cancer the chemotherapy regimen was an effective form of palliative treatment.

\section{Introduction}

Chemotherapeutic management of advanced colorectal cancer has been a challenge to medical oncologists for the past three decades. Although tumours in $15-20 \%$ of patients have responded to fluorinated pyrimidines, in particular 5-fluorouracil, there has been no evidence of improved survival. Empirically derived combinations of chemotherapeutic drugs have given disappointing results. ${ }^{2}$ Recent attempts to enhance the therapeutic activity of 5fluorouracil have focused on biochemical modulation: several randomised studies have shown that its effect is greater when used in combination with leucovorin.' The optimal dose, schedule, and route of administration, however, have not been established. Complete response is rare, and the improvement in median survival seems small. Furthermore, most 5-fluorouracil and leucovorin dose schedules have a high incidence of severe gastrointestinal side effects ${ }^{3}$ and may thus interfere with the patients' quality of life, one of the most important aspects to be considered in palliative treatment.

Because of uncertainty about the true palliative benefit of combined regimens we conducted a randomised study of the effects of chemotherapy and supportive care on survival and quality of life of patients with colorectal cancer. The chemotherapeutic regimen chosen was a combination of 5-fluorouracil and leucovorin with cisplatin. Cisplatin was included 
because of experimental evidence that it further potentiates inhibition of thymidylate synthase, ${ }^{45}$ its encouraging therapeutic results in pretreated breast and advanced head and neck cancer, ${ }^{67}$ and the recent demonstration of a good therapeutic index in metastatic colorectal cancer. $^{8}$

\section{Patients and methods}

Patients who had inoperable, measurable, histologically confirmed metastatic or locally recurrent adenocarcinoma of the colon or rectum were eligible for entry into the study. Additional requirements for inclusion in the study were age under 75 years, life expectancy over two months, Eastern Cooperative Oncology Group performance status $\leqslant 3$, no previous chemotherapy, and adequate haematological (leucocyte count $>4 \times 10^{\circ} /$, platelet $\left.>150 \times 10^{\circ} / 1\right)$, hepatic (no jaundice and serum aminotransferase concentrations $<100 \mathrm{IU} / \mathrm{l}$ ), and renal (serum creatinine $<132.6 \mu \mathrm{mol} / \mathrm{l}$, creatinine clearance $>1 \mathrm{ml} / \mathrm{s}$ ) functions.

After fully informed consent was obtained eligible patients were registered by phone at the central statistical office at the University of Vienna. They were allocated randomly to receive supportive care plus chemotherapy (arm A) or supportive care only (arm B) in the ratio of $2: 1$ (which was based on the assumption of a higher refusal rate in arm B). The assignment was determined by randomisation in blocks of six (as defined by a computer generated random number list) according to performance status (score $0-1 \quad v \quad 2-3$ ), metastatic disease of the liver (assessed by ultrasonography or computed tomography, or both), and weight loss in the six months before entering the study. Supportive care consisted of analgesics, nutritional support, blood transfusions to correct severe anaemia, and psychosocial support. Chemotherapy consisted of leucovorin $200 \mathrm{mg} / \mathrm{m}^{2} /$ day by intravenous push followed 30 minutes later by bolus 5 -fluorouracil $550 \mathrm{mg} / \mathrm{m}^{2} /$ day and cisplatin $20 \mathrm{mg} / \mathrm{m}^{2} /$ day, given as a two hour infusion with adequate hydration. An antiemetic regimen comprising dexamethasone, metoclopramide, and lorazepam was routinely used. All chemotherapeutic drugs were given on four consecutive days at four week intervals for a total of six months or until there was evidence of tumour progression.

Quality of life was assessed at entry to the study and every two months with the functional living index for cancer (FLIC). This is a contemporary, well validated, 22 item self report scale developed for repeated use by patients with cancer. ${ }^{9}$ It provides a single quality of life score based on indices of perceived physical wellbeing, psychological state, and sociability. To counteract difficulties in collection and methodological evaluation of the data ${ }^{10}$ we used several refinements of the method, including designation of a central data coordinator and use of a simple 10 point (rather than a continuous) scale. Furthermore, serial results in individual patients at successive time points have been evaluated according to the criteria proposed by Presant et al for assessing palliative response by quality of life (box). ${ }^{11}$ Analyses of changes in quality of life were performed separately for patients whose scores were all normal before treatment and for patients who had at least one score (global score or subgrouping) that was abnormal -that is, more than two standard deviations above results in normal people. ${ }^{11}$ Twenty healthy volunteers completed the questionnaire. They had a mean score of 41 (SD 16), and this was used to define a normal value. The duration of palliative response was measured from the time that the response was first observed until a significantly lower score was obtained on two successive measurements. A significant change in score was defined by the $95 \%$ confidence interval of the in-

\section{Criteria for assessing palliative response through quality of life proposed by} Presant et $a l^{11}$

Patients with normal pretreatment scores ${ }^{\star}$

Maintained complete palliative response-No global or subgrouping score drops below normal range for two or more successive measurements

Worse quality of life-A global or subgrouping score drops below normal range for at least two successive measurements. The score is significantly below the baseline valuef or patient dies

Patients with abnormal pretreatment scores $\ddagger$

Complete palliative response-All global and subgrouping scores increase to within normal range for at least two successive measurements

Partial palliative response-At least one global or subgrouping score increases significantly on at least two successive measurements, with no score decreasing significantly

Stable quality of life-No significant change in any quality of life score during study for at least two successive measurements

Worse quality of life-At least one global or subgrouping score decreases significantly on two successive measurements or patient dies

*Quality of life global score and all subgroupings are within two standard deviations of scores in normal populations before treatment is started.

†Defined by the $95 \%$ confidence intervals of the instrument assessed in test-retest analysis during the early part of this trial.

$\ddagger$ At least one global or subgrouping score is below normal before treatment.

strument on test-retest analysis assessed during the early part of this trial.

Treatment related toxicity and antitumour responses were assessed periodically in both groups according to World Health Organisation standard criteria. ${ }^{12}$ The length of time to disease progression and survival time, both calculated from the date of randomisation, were analysed by the Kaplan-Meier product limit method. ${ }^{13}$ Differences between groups were evaluated by the logrank test. ${ }^{14}$

\section{Results}

Between April 1988 and September 1989, 40 patients were accrued to the study. Two patients in each treatment arm refused to accept the treatment assigned or participate in the research study, or both. Thus, 36 patients were eligible for analysis of response and toxicity. Of these, 24 were randomised to receive chemotherapy with 5-fluorouracil, leucovorin, and cisplatin (arm A) and 12 to receive no chemotherapy (arm B). During the study two patients randomised to no chemotherapy were treated with 5-fluorouracil alone when symptomatic tumour progression occurred. This decision was made by the patients' doctors; neither patient responded, but both have been included in this analysis.

The pretreatment characteristics of patients in the two groups were similar (table I), although the median time from original diagnosis of colorectal cancer to entry was slightly longer for patients with chemotherapy ( 8.5 (range 0 to 61 ) months) than for those who received supportive care alone ( 5.5 ( 0 to 22$)$ months).

Table II summarises the results of chemotherapy or supportive care in the two groups. Of the 24 patients randomised to chemotherapy, eight partially responded. The median number of treatment cycles administered was 4.5 (range 1 to 8 ), and the median duration of response was 35 (16 to 56) weeks. Nine patients $(38 \%)$ had stable disease and seven $(29 \%)$ progressive disease. Three (25\%) of the 12 patients randomised to no chemotherapy were classified as 
TABLE I-Patient characteristics by treatment group. Values are numbers (percentages) unless stated otherwise

\begin{tabular}{|c|c|c|c|}
\hline Characteristic & $\begin{array}{l}\text { Chemotherapy } \\
\quad(n=24)\end{array}$ & $\begin{array}{l}\text { No chemotherapy } \\
(n=12)\end{array}$ & $\begin{array}{c}\text { All } \\
\text { patients } \\
(\mathrm{n}=36)\end{array}$ \\
\hline \multicolumn{4}{|l|}{ Evaluable patients: } \\
\hline \multicolumn{4}{|l|}{ Sex: } \\
\hline Male & $10(42)$ & $7(58)$ & 17 \\
\hline Female & $14(58)$ & $5(42)$ & 19 \\
\hline \multicolumn{4}{|l|}{ Performance status ${ }^{\star}$ : } \\
\hline $0-1$ & $16(67)$ & $8(67)$ & 24 \\
\hline $2-3$ & $8(33)$ & $4(33)$ & 12 \\
\hline \multicolumn{4}{|l|}{ Weight loss: } \\
\hline None & $16(67)$ & $8(67)$ & 24 \\
\hline Yes & $8(33)$ & $4(33)$ & 12 \\
\hline \multicolumn{4}{|l|}{ Location of primary tumour: } \\
\hline Colon & $14(58)$ & $8(67)$ & 22 \\
\hline Rectum & $10(42)$ & $4(33)$ & 14 \\
\hline \multicolumn{4}{|l|}{ Liver metastases: } \\
\hline Yes & $12(50)$ & $6(50)$ & 18 \\
\hline No & $12(50)$ & $6(50)$ & 18 \\
\hline \multicolumn{4}{|l|}{ No of metastatic lesions: } \\
\hline 1 & $8(33)$ & $5(42)$ & 13 \\
\hline$>1$ & $16(67)$ & $7(58)$ & 23 \\
\hline \multicolumn{4}{|l|}{ Histological grade: } \\
\hline 1 & $5(21)$ & $3(25)$ & 8 \\
\hline 2 & $16(67)$ & $8(67)$ & 24 \\
\hline 3 & $3(12)$ & $1(8)$ & 4 \\
\hline
\end{tabular}

^Eastern Cooperative Oncology Group scale.

TABLE II-Results of treatment in patients with metastatic colorectal cancer

\begin{tabular}{lcl}
\hline & $\begin{array}{c}\text { Chemotherapy } \\
(\mathrm{n}=24)\end{array}$ & $\begin{array}{c}\text { No } \\
\text { chemotherapy } \\
(\mathrm{n}=12)\end{array}$ \\
\hline $\begin{array}{l}\text { Treatment response: } \\
\quad \text { Complete }\end{array}$ & \\
$\quad$ Partial & $8(33)$ & \\
Stable disease & $9(38)$ & $3(25)$ \\
$\quad$ Progression & $7(29)$ & $9(75)$ \\
Median (range) survival (months) & $11 \cdot 0(3 \cdot 0-37 \cdot 0)$ & $5 \cdot 0(1 \cdot 5-23 \cdot 0)$ \\
Condition at end of study: & $3(13)$ & \\
Alive & $21(87)$ & $12(100)$ \\
Dead & & \\
\hline
\end{tabular}

having stable disease and nine $(75 \%)$ as having progressive disease. Median time to progression was 6.0 (2 to 14) months for treated patients and $2 \cdot 3(1.5$ to 8.0$)$ months for controls; this difference was significant $(p=0.0008)$.

Thirty three of the 36 patients in the study had died at the end of the study period, $21(87 \%)$ in the chemotherapy group and all 12 in the supportive care group. The minimum follow up of the three survivors was 28 months. Figure 1 gives the actuarial survival curves for all subjects by randomisation status (including the four patients who refused the assigned treatment). The curves for the two groups were significantly different $(p=0 \cdot 006)$. Median survivals were $11.0(4 \cdot 0$ to 37.0 ) months for patients randomised to chemotherapy and 5 (1.5 to 23$)$ months for those receiving supportive care. The sample size was too small to rule out any differences in survival between patients of different prognostic groups.

Toxicity was common in the chemotherapy group, though symptoms were generally mild to moderate. No patient stopped chemotherapy because of side effects, and only two had to have the dose reduced (by $25 \%$ ) because of grade 3 haematological and gastrointestinal side effects (table III). In the supportive care group, mild nausea, diarrhoea, and infection were indicated by two, three, and one patient, respectively; no other systemic toxicities were recorded.

Eighteen $(75 \%)$ patients who received chemotherapy and eight $(67 \%)$ symptomatically treated patients completed at least two questionnaires on quality of life, including one at baseline, and were thus considered evaluable. The remaining patients were unwilling to complete the form (two), had problems with reading because of poor vision or language (two), or died early (six). An average of five evaluations was available for all patients (range 3 to 10). The mean total scores in the chemotherapy group (87.5 (SD 44)) and in the supportive care group $(80 \cdot 2(40))$ were similar at baseline, as were mean factor scores.

Table IV gives the quality of life in the two treatment groups. Overall, there was no difference between the two patient groups, though in patients with abnormal scores before treatment the quality of life seemed better in the chemotherapy group. In the chemotherapy group a transient slight deterioration in quality of life was noticed during treatment with cytotoxic drugs (fig 2). Thereafter, quality of life improved compared with baseline and with patients in the supportive care group. In the supportive care group supportive drugs resulted in an initial improvement of the quality of life. The improvement was short lived, however, because of disease progression. No significant difference was found between the scores in the two groups.

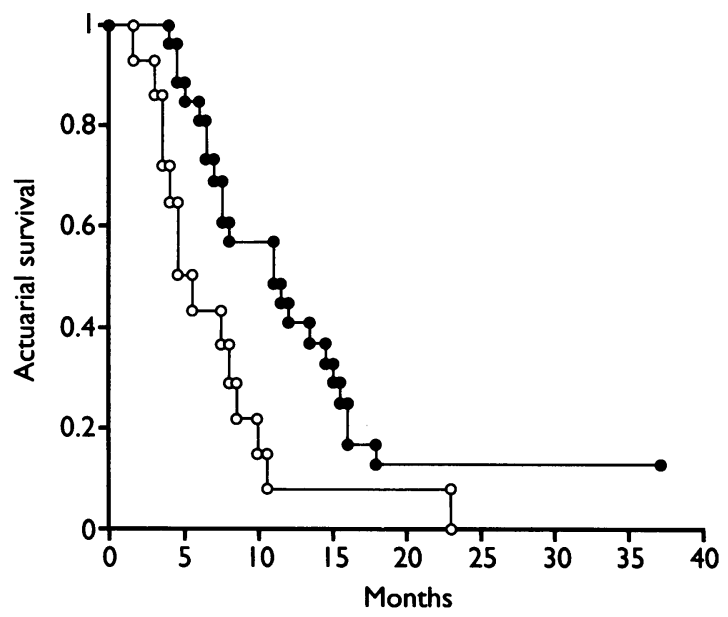

1-Survival of patients with metastatic colorectal cancer randomised to chemotherapy plus supportive care (-) and to supportive care alone $(\mathrm{O}-\mathrm{O})$

TABLE III-Severity of side effects by World Health Organisation grade in 24 patients receiving chemotherapy with 5-fluorouracil, leucovorin and cisplatin

\begin{tabular}{lcccc}
\hline & \multicolumn{4}{c}{ WHO grade } \\
\cline { 2 - 5 } Side effect & None & 1 & 2 & 3 \\
\hline Gastrointestinal: & & & & \\
$\quad$ Nausea or vomiting & 10 & 7 & 6 & 1 \\
$\quad$ Diarrhoea & 17 & 4 & 3 & 0 \\
$\quad$ Stomatitis & 21 & 2 & 1 & 0 \\
Haematological: & 15 & 5 & 3 & 1 \\
$\quad$ Leucopenia & 19 & 3 & 2 & 0 \\
$\quad$ Anaemia & 22 & 1 & 1 & 0 \\
$\quad$ Thrombocytopenia & & 3 & 1 & 0 \\
Other symptoms: & 20 & 22 & 0 & 0 \\
$\quad$ Alopecia & 22 & 2 & 0 & 0 \\
$\quad$ Neuropathy & 23 & 1 & 0 & 0 \\
$\quad$ Nephrotoxicity & 23 & 1 & & \\
Infection & & &
\end{tabular}

TABLE IV-Quality of life* in patients with metastatic colorectal cancer by treatment group

\begin{tabular}{|c|c|c|}
\hline & Chemotherapy & $\begin{array}{c}\text { No } \\
\text { chemotherapy }\end{array}$ \\
\hline \multicolumn{3}{|l|}{ Patients with normal scores } \\
\hline Maintained complete & & \\
\hline palliative response & 5 & 3 \\
\hline Worse quality of life & 3 & \\
\hline $\begin{array}{l}\text { Patients with abnormal } \\
\text { scores before treatment } \\
\text { Complete palliative }\end{array}$ & 10 & 5 \\
\hline response & 3 & \\
\hline Partial palliative response & 4 & 2 \\
\hline Stable quality of life & 3 & 1 \\
\hline Worse quality of life & & 2 \\
\hline \multirow{2}{*}{$\begin{array}{l}\text { Overall response rate } \\
\text { Median (range) duration of } \\
\text { response (months) }\end{array}$} & $12 / 18(67 \%)$ & $5 / 8(62 \%)$ \\
\hline & $7(4$ to 18$)$ & $6(4$ to 9$)$ \\
\hline
\end{tabular}

*Measured by the functional living index for cancer. Normal score was defined as within two standard deviations of scores in healthy populations. 


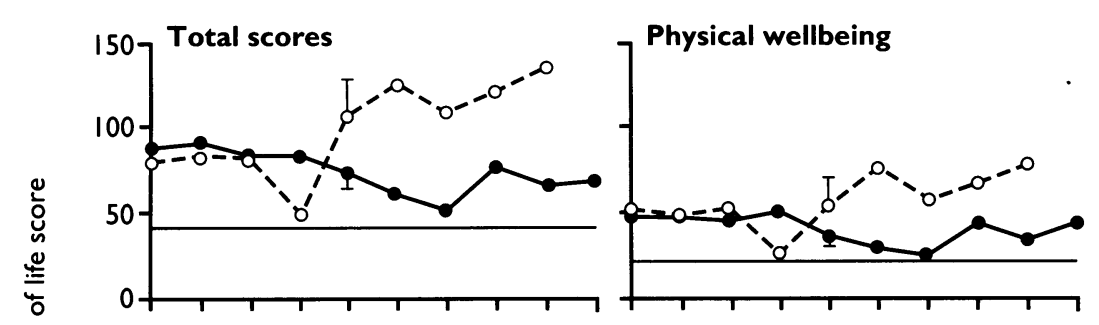

वิำ

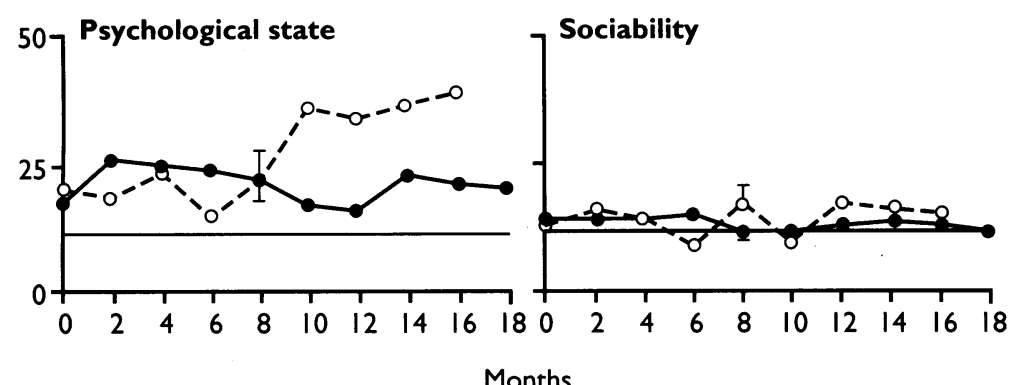

FIG 2-Median quality of life scores assessed by functional living index for cancer in patients treated with chemotherapy plus supportive care (-) or supportive care alone $(\mathrm{O}-\mathrm{O})$. Low score indicates improved quality of life. Representative single standard errors are shown at eight months. Horizontal lines indicate mean quality of life scores among 20 healthy volunteers

\section{Discussion}

Many doctors and their patients reject conventional anticancer chemotherapy for disseminated colorectal cancer in favour of unproved alternatives because of uncertainty about therapeutic gain and concern about toxic effects. Whether and how much chemotherapy prolongs survival in advanced colorectal cancer, despite its use for several decades, is not known. 5-Fluorouracil, which was the standard treatment until one or two years ago, was not considered to prolong median survival, although a controlled trial against no chemotherapy has never been done. ${ }^{1}$ Several trials comparing 5-fluorouracil alone with combinations based on biochemical modulation have indicated better objective tumour response with the combination treatment. ${ }^{3} \mathrm{An}$ improvement in survival with combinations of 5-fluorouracil and leucovorin, however, has been observed in only two of seven randomised studies, ${ }^{315}$ and the improvement was only moderate..$^{15} 16$

We found that combination chemotherapy with 5-fluorouracil, leucovorin, and cisplatin in patients with metastatic colorectal cancer increased time to progression and length of survival compared with those in patients given only supportive care. Because of the small numbers of patients studied, our findings are only preliminary. Nevertheless, the median increase in survival in patients receiving chemotherapy was six months, during which time, overall quality of life was at least as good as in patients receiving supportive care. In patients with symptomatic disease the quality of life, in fact, seemed better in the chemotherapy arm despite its common association with mild to moderate gastrointestinal side effects.

The advantage of chemotherapy in previously asymptomatic patients might be questioned in view of the side effects and the initial, though only minor and transient, decrease in patients' subjective wellbeing. However, our study was conducted before ondansetron became available, which in our experience would probably have prevented the initial decrease in quality of life in patients receiving cisplatin. Furthermore, the overall gain in time to progression and length of survival was seen in patients both with and without tumour related symptoms. The potential advantage of early treatment in asymptomatic patients with advanced colorectal cancer seems to have been confirmed by a trial from the Nordic Gastrointestinal Tumor Adjuvant Therapy Group. ${ }^{17}$ Further advances in the knowledge of prognostic factors should help to identify subgroups of (asymptomatic) patients with a more prolonged clinical course, in whom a wait and see policy seems adequate.

Whether the addition of cisplatin to 5-fluorouracil and leucovorin had any influence on the apparent beneficial effect of palliative chemotherapy in this study remains uncertain. Comparison of objective tumour response rate and median survival time in our chemotherapy group and in phase II and III studies with conventional 5-fluorouracil and leucovorin regimens $^{3}$ suggest that this is not the case. Severe toxicity was less common in our study, however, and the three drug combination seems to have a better therapeutic index. ${ }^{818}$

In conclusion, our data indicate that chemotherapy with 5-fluorouracil, leucovorin, and cisplatin improves quality of life in symptomatic patients with metastatic colorectal cancer and prolongs survival. Although the small numbers studied reduces the strength of our results, they support previous, indirect evidence of a beneficial effect of chemotherapy in this disease. In addition, the distribution of characteristics known to affect survival in colorectal cancer ${ }^{19}$ was similar in the two study groups. 1 Moertel CG, Thynne GS. Large bowel. In: Holland JF, Frei E, eds. Cancer
medicine. Philadelphia: Lea and Febiger, 1982:1830-59.

2 Davis HL. Chemotherapy of large bowel cancer. Cancer 1982;50:2638-46.

3 Arbuck SG. Overview of clinical trials using 5-fluorouracil and leucovorin for the treatment of colorectal cancer. Cancer 1989;63:1036-44.

4 Etienne MC, Bernard S, Fischel JL, Formento P, Gioanni J, Santini J, et al. Dose reduction without loss of efficacy for 5 -fluorouracil and cisplatin combined with folinic acid. In vitro studies on human head and neck carcinoma cell lines. Br f Cancer 1991;63:372-7.

5 Scheithauer W, Temsch EM. A study of various strategies to enhance the cytotoxic activity of 5 -fluorouracil/leucovorin in human colorectal cancer cell lines. Anticancer Res 1989;9:1793-8.

6 Hart L, Chua C, Brophy L. Salvage chemotherapy for metastatic breast carcinoma using cisplatin, fluorouracil and leucovorin: a phase I-II study. Proc Am Soc Clin Oncol 1989;8:43.

7 Vokes EE, Schilsky RL, Weichselbaum RR, Guaspari A, Guarnieri CM Whaling SM, et al. Induction chemotherapy with cisplatin, fluorouracil, and high-dose leucovorin for locally advanced head and neck cancer: a clinical high-dose leucovorin for locally advanced head and neck

8 Scheithauer W, Rosen H, Schiessel R, Schüller J, Karall M, Ernst F, et al. Treatment of patients with advanced colorectal cancer with cisplatin,
, ethauer W, Rosen H, Schiessel R, Schüller J, Karall M, Ernst F, al. 5-fluorouracil, and leucovorin. Cancer 1991;67:1294-8.

9 Schipper H, Clinch J, McMurray A, Levitt M. Measuring the quality of life of cancer patients: the functional living index-cancer: development and validation. I Clin Oncol 1984;2:472-83.

10 Ganz PA, Figlin RA, Haskell CM, Sofo NL, Siari J. Supportive care versus supportive care and combination chemotherapy in metastatic non-small cell lung cancer. Cancer 1989;63:1271-8.

11 Presant CA, Wiseman C, Blayney D, Kennedy P, Gala K, King M. Proposed criteria for serial evaluation of quality of life in cancer patients. 7 Natl Cancer Inst 1990;82:322-3.

12 Miller AB, Hoogstraten B, Staquet M. Reporting results of cancer treatment. Cancer 1981;47:207-14.

13 Kaplan EL, Meier P. Nonparametric estimation from incomplete observations. Journal of the American Statistical Association 1958;53:457-81.

14 Peto R, Pike MC, Armitage P, Breslow NE, Cox DR, Howard SV, et al Design and analysis of randomized clinical trials requiring prolonged observation of each patient. II. Analysis and examples. $\mathrm{Br}$ f Cancer 1977;35:1-39.

15 Poon MA, O'Connell MJ, Moertel CG, Wieand HS, Cullinan SA, Everson $\mathrm{LK}$, et al. Biochemical modulation of fluorouracil: evidence of a significan improvement of survival and quality of life in patients with advanced colorectal carcinoma. f Clin Oncol 1989;10:1407-18.

16 Erlichman C, Fine S, Wong A, Elhakim T. A randomized trial of fluorouracil and folinic acid in patients with metastatic colorectal carcinoma. I Clin Oncol 1988;6:469-75.

17 The Nordic Gastrointestinal Tumor Adjuvant Therapy Group. Expectancy or primary chemotherapy in patients with asymptomatic colorectal cancer: a primary chemotherapy in patients with asympt
randomized trial. F Clin Oncol 1992;6:904-11.

18 Scheithauer W, Kornek G, Depisch D, Rosen H, Sebesta C, Walzl B, et al. Phase III study of fluorouracil (FU) and leukovorin (LV) with or without cisplatin (CDDP) in patients with advanced colon cancer [abstract]. Proc Am cisplatin (CDDP) in patien

19 Lavin P, Mittelman A, Douglass H Jr, Engstrom P, Klaassen D. Survival and response to chemotherapy for advanced colorectal adenocarcinoma. Cancer 1980;46:1536-43.

(Accepted 25 January 1993) 